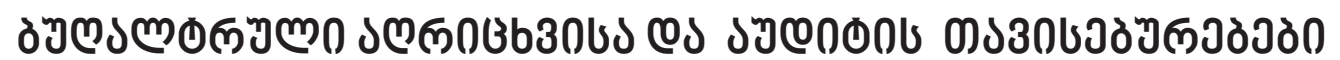

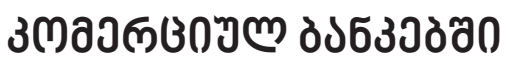

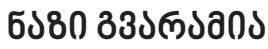

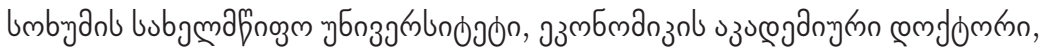

https://doi.org/10.35945/gb.2017.04.011

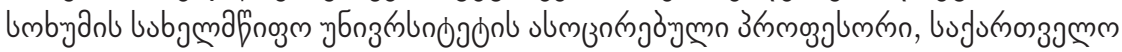

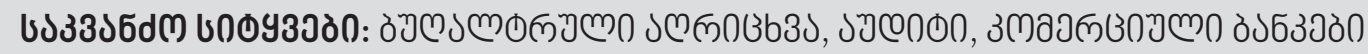

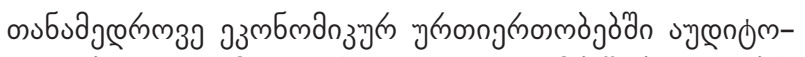

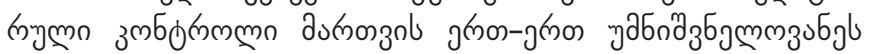

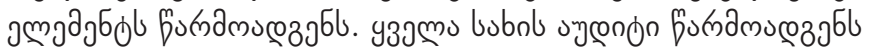

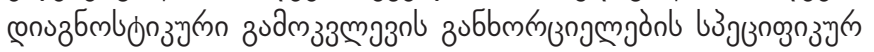

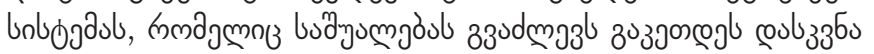
m nुas

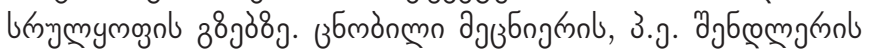

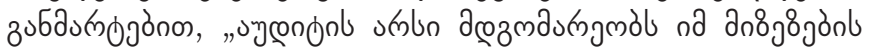

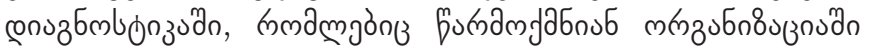

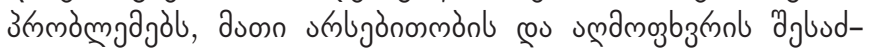

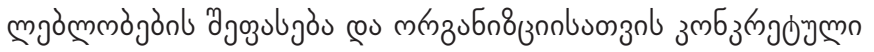

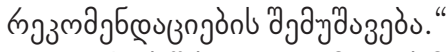

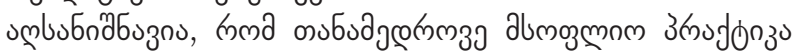

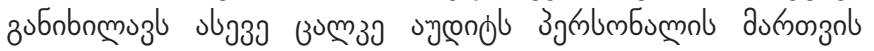

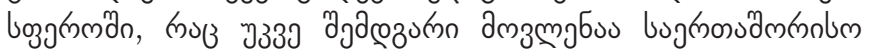

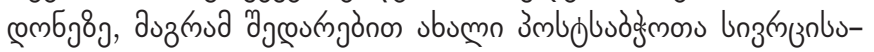

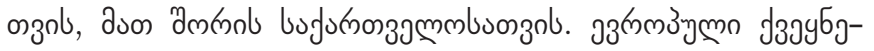

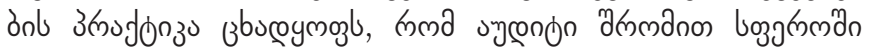

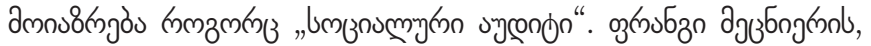
bmżus

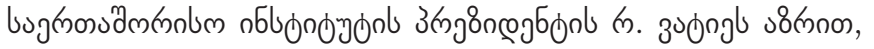

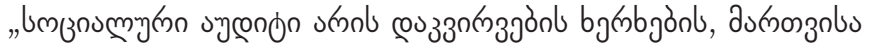

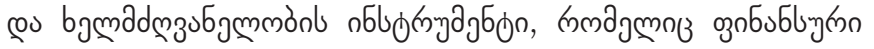

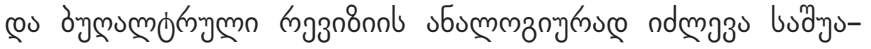

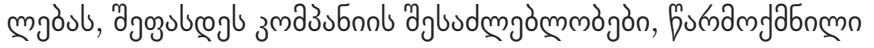

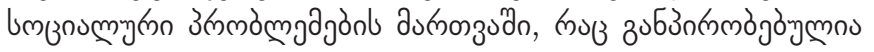

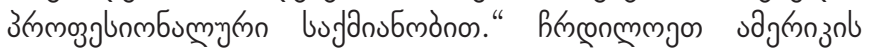

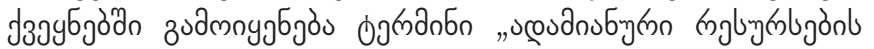

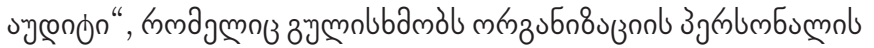

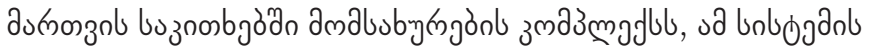

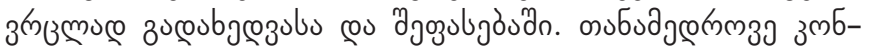

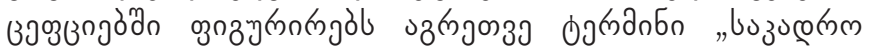

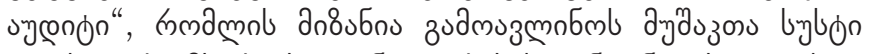

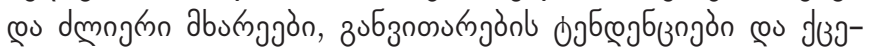

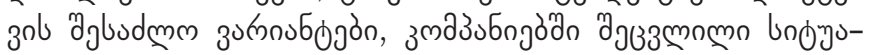

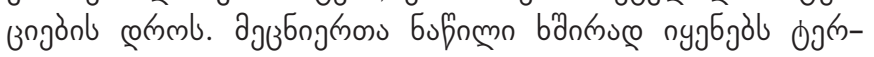

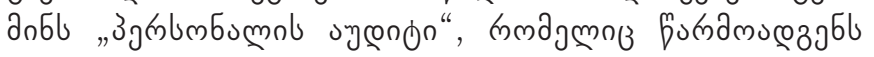

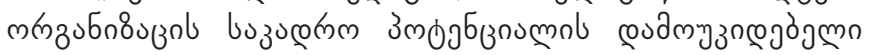

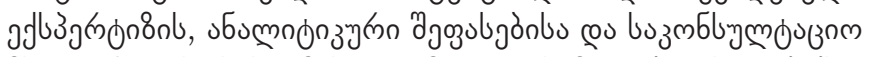

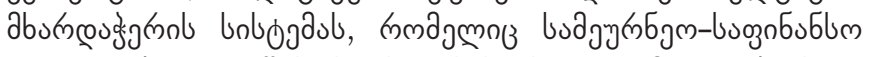

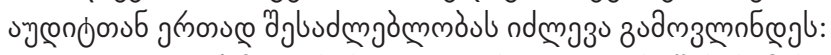

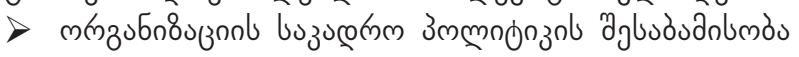

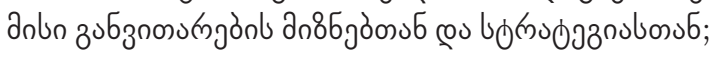

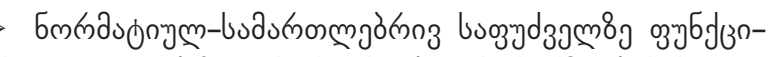

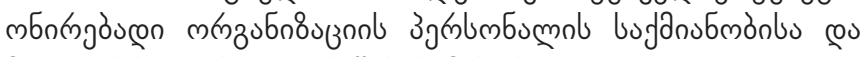

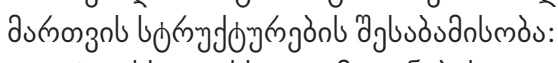

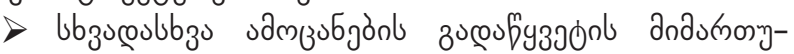

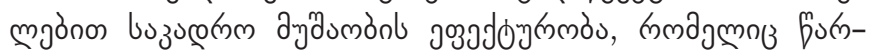

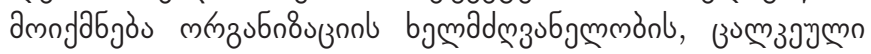

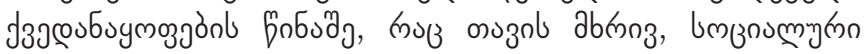

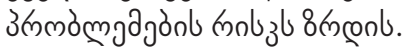

8 дамm uल

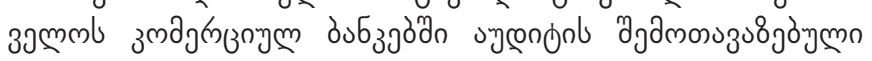

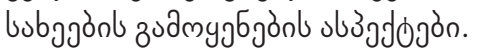

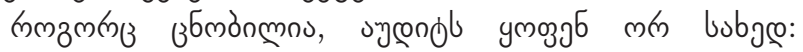

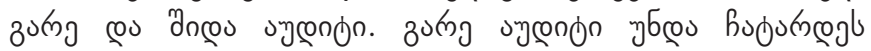

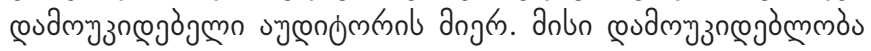

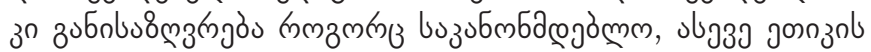

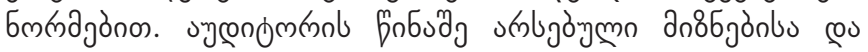

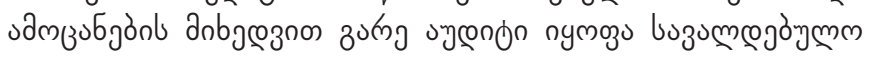

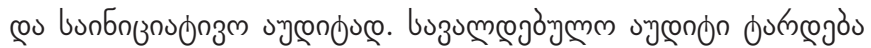

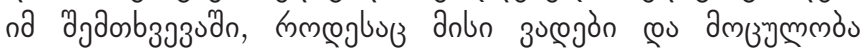

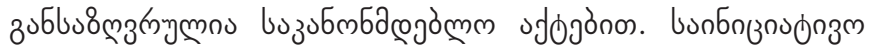

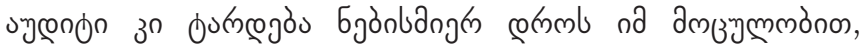

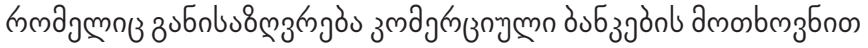

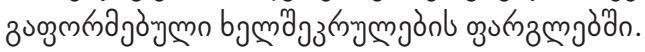

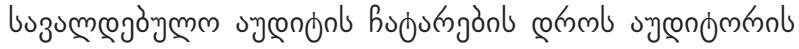

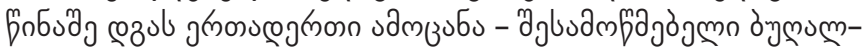

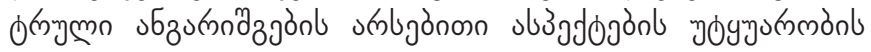

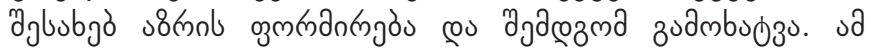

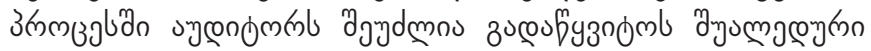

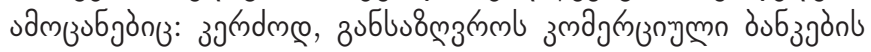

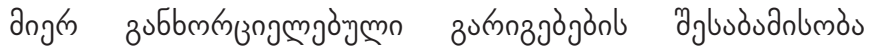

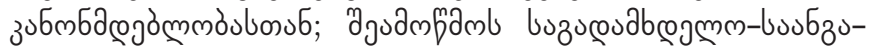

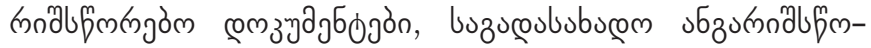

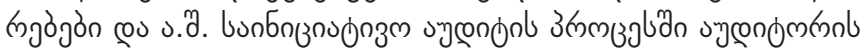

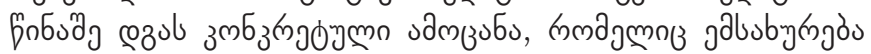

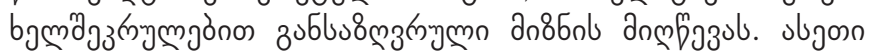

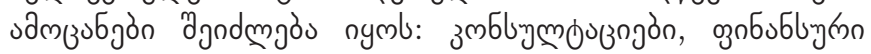

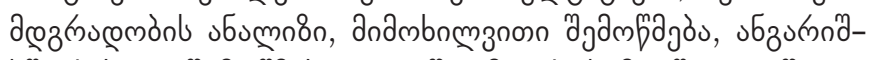

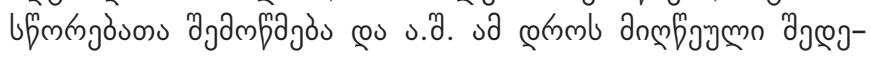

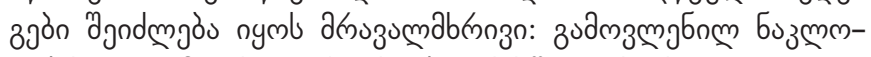

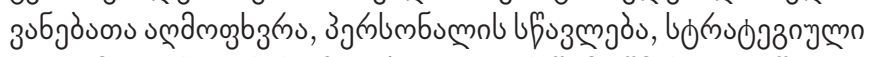

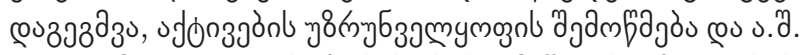

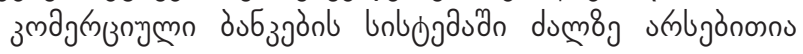

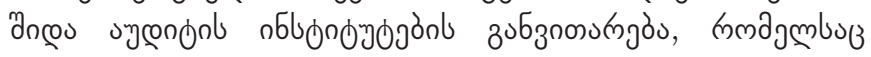




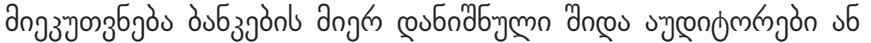

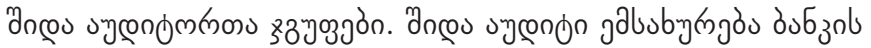

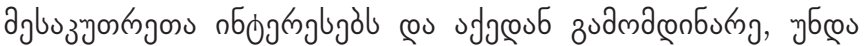

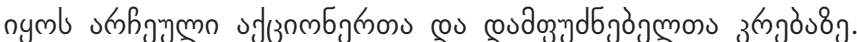

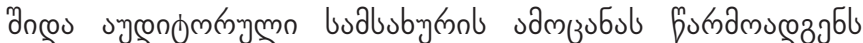

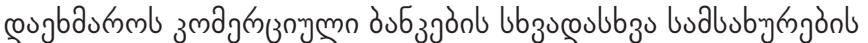

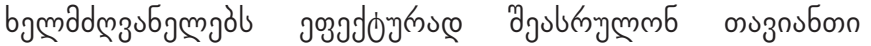

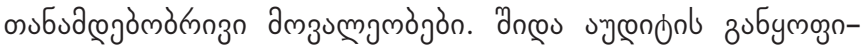
mgà furmamuœ

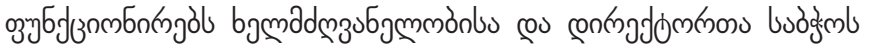

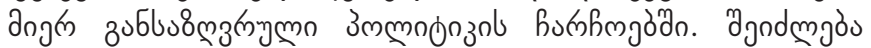

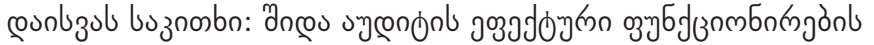

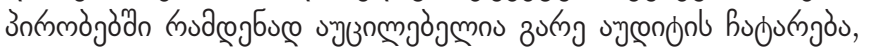

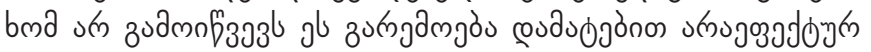

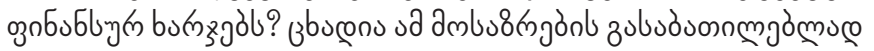

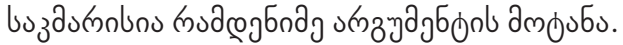

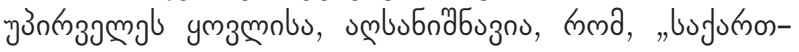

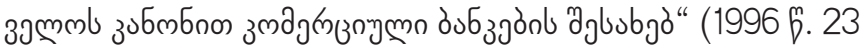

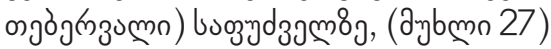

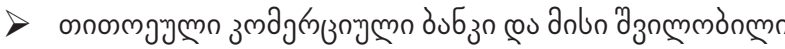

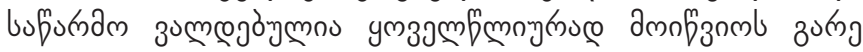

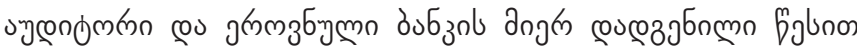

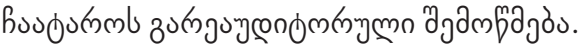

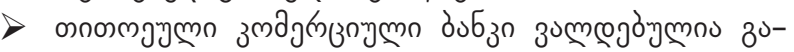

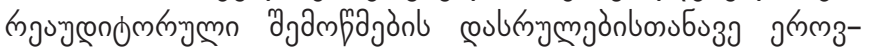

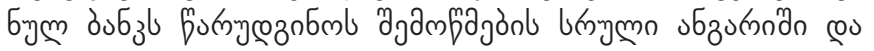

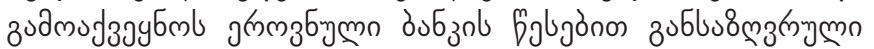

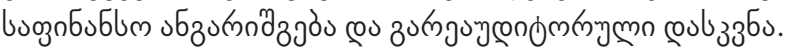

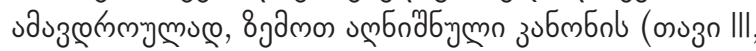

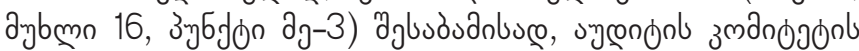

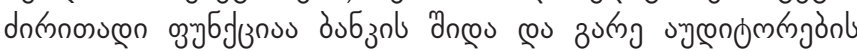

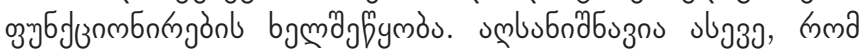

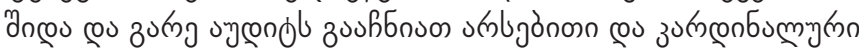

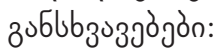

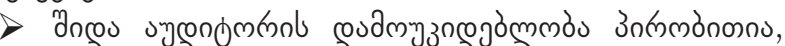

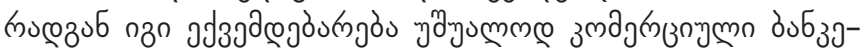
onl bymadmas

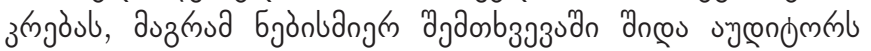

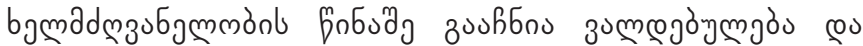

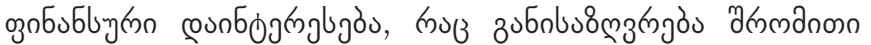

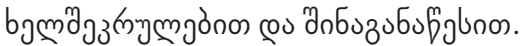

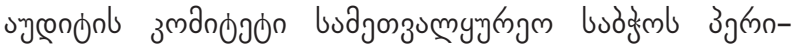

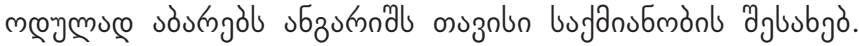

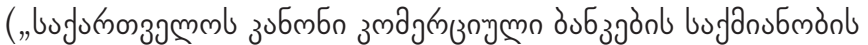

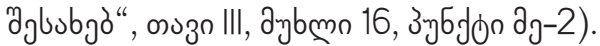

$>$ Incos sygononl anszum samgubsls furmamugzjbl

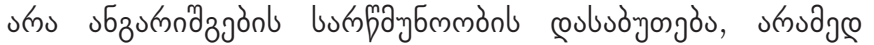

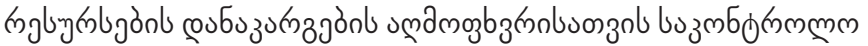

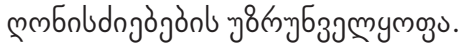

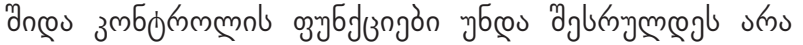

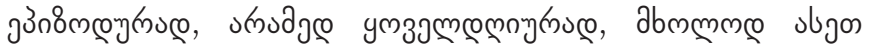

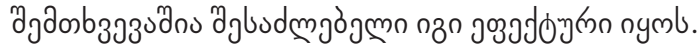

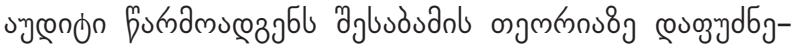

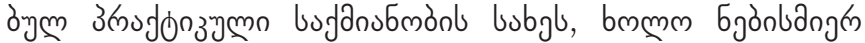

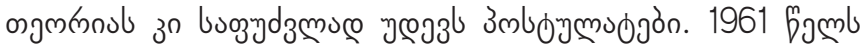

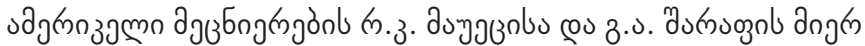

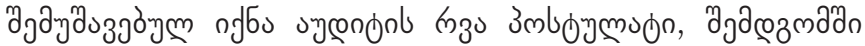

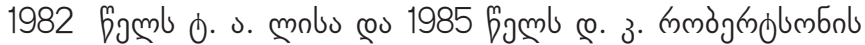

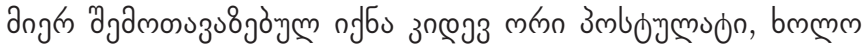

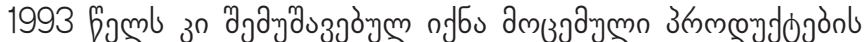

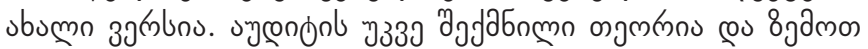

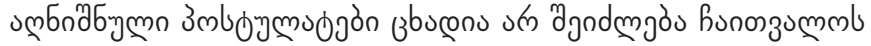

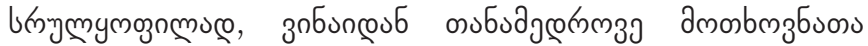

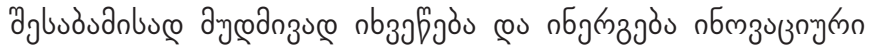

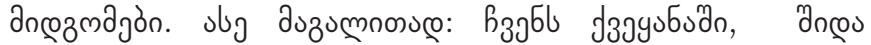

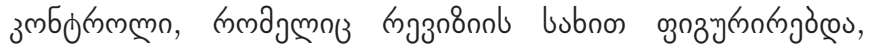

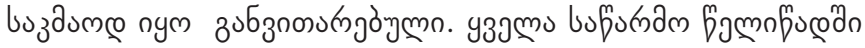

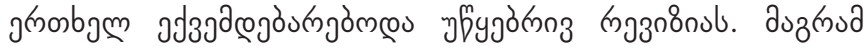

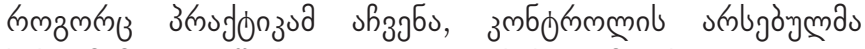

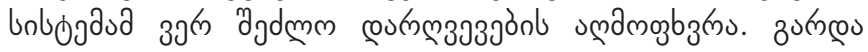

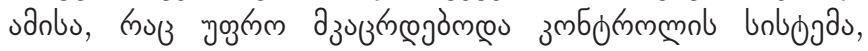

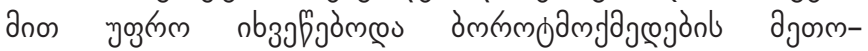

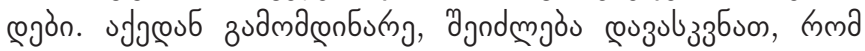

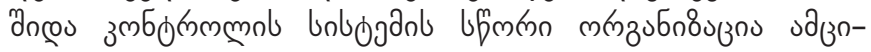

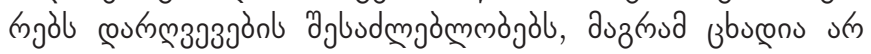

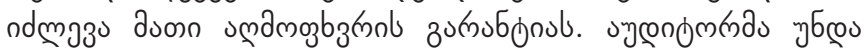

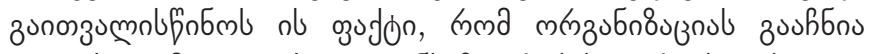

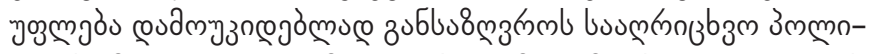

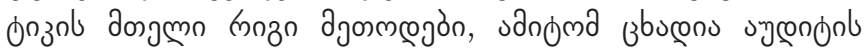

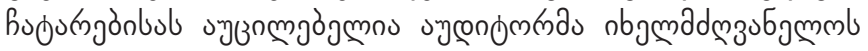
s

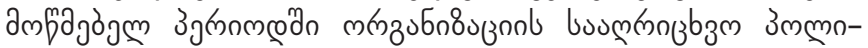

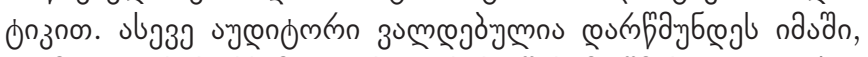

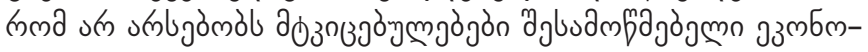

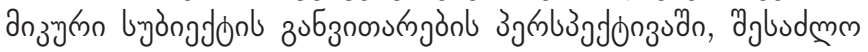
bgnпm8

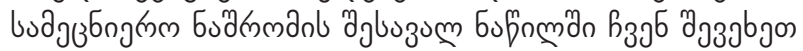

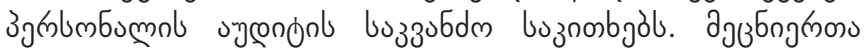

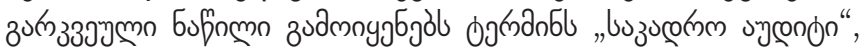

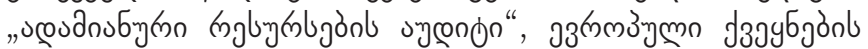

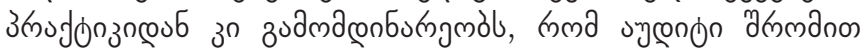

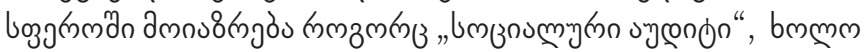

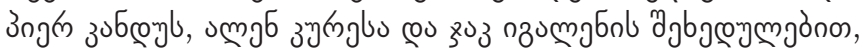

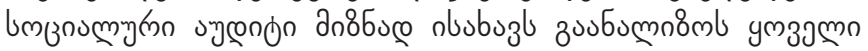

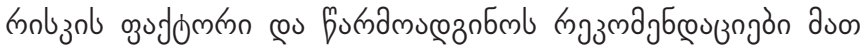

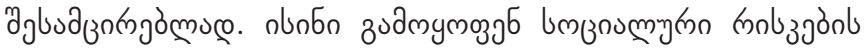
monb zod 3 mmonol:

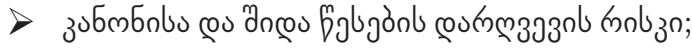

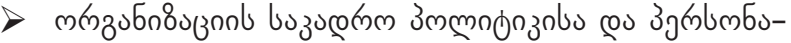

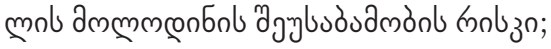

$>$ vecadnuby

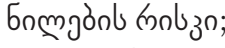

moliza.

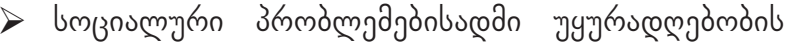

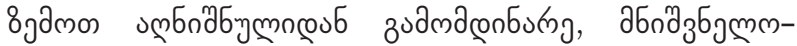

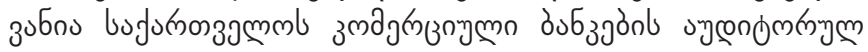




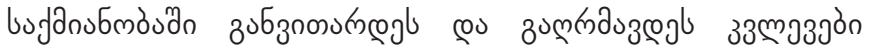

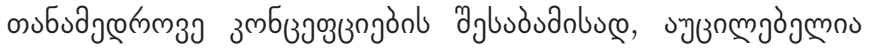

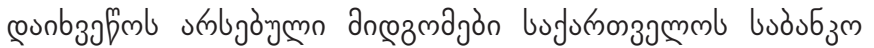

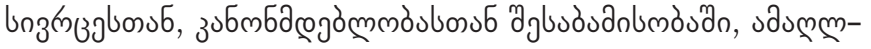

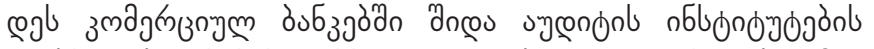

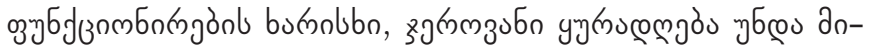
aلsal s s.

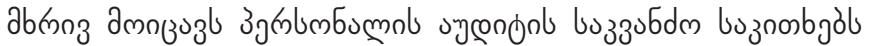

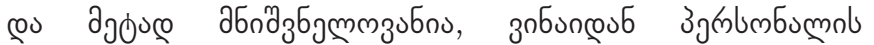

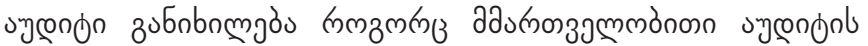

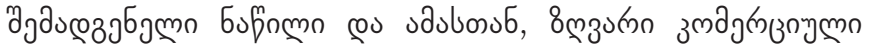

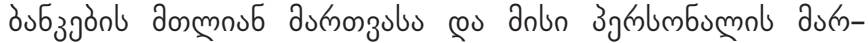

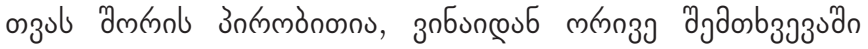

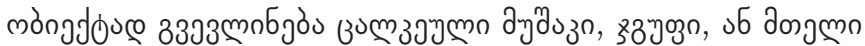

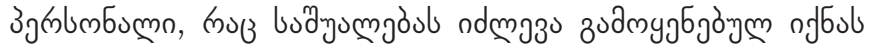

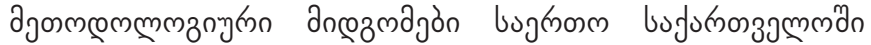

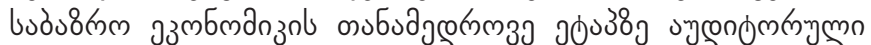

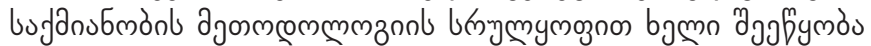

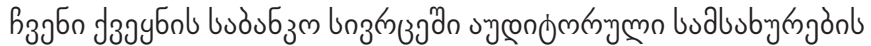

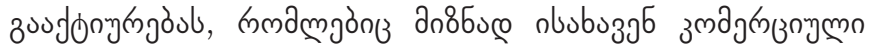

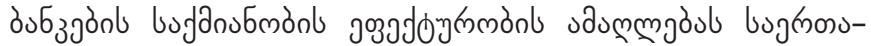

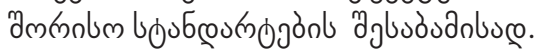

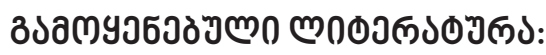

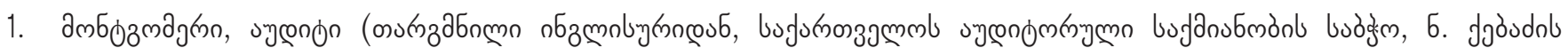

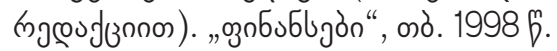

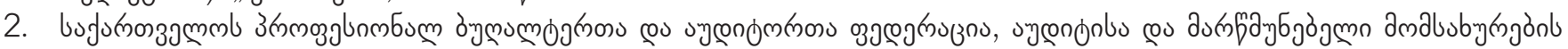

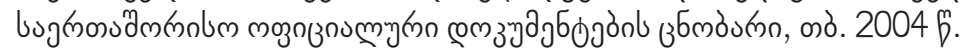

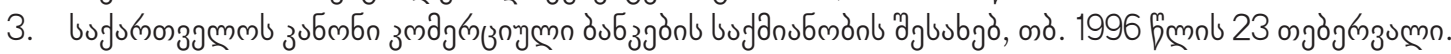

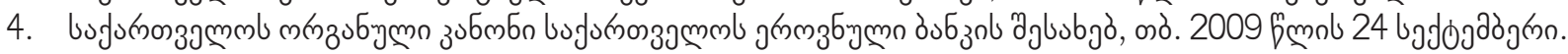

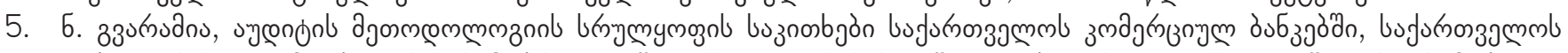

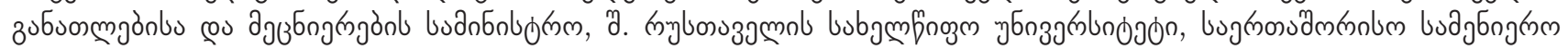

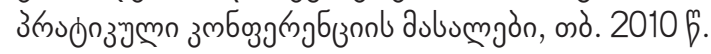

6. Жак Ришар. Аудит и анализ хозяйственной деятельности предприятия (перевод с француз. под ред. Л. П. Белых), Москва, « Аудит» 1997 г.

7. И. Колбасов. Журнал «Аудит»; №10., 2008 г. 


\section{ACCOUNTING AND AUDITING PECULIARITIES OF COMMERCIAL BANKS}

\section{NAZI GVARAMIA}

https://doi.org/10.35945/gb.2017.04.011

Doctor of Economics, Associated Professor of Sokhumi State University, Georgia

KEYWORDS: ACCOUNTING, AUDIT, COMMERCIAL BANKS

\section{SUMMARY}

The scientific work presents the world concepts in the sphere of audit on the modern stage, including, of course, the experience of European countries in the mentioned direction. Main aspects of "social", "staff" and "personnel audit" been already approved in international practice are discussed, risks connected to social audit are highlighted as well as the types of audit are described and given in Georgian commercial banks according to applicable law in our country. Besides, the work is about major issues of carrying out inner and outer audit.
The work emphazises the role and importance of audit in modern management systems and this gives an opportunity to make a clear decision in connection with the quality of effectiveness of a company's activity and its perfection. Hence, the scientific work is about the problems of importance of development of inner audit institutions in Georgian commercial banks, and recommendation offers and opinions on perfection of methodology of audit are given, accordingly. 